\title{
Targeted temperature management and neuroprotective outcomes of pediatric patients after cardiac arrest
}

Yun-Jin Lee, MD, PhD ${ }^{1,2}$

${ }^{1}$ Department of Pediatrics, Pusan National University Children's Hospital, Pusan National University School of Medicine, Yangsan, Korea; ${ }^{2}$ Research Institute for Convergence of Biomedical Science and Technology, Pusan National University Yangsan Hospital, Yangsan, Korea

Post-cardiac arrest care (PCAC) differs by both post-cardiac arrest syndrome phase and the setting in which care is delivered after return of spontaneous circulation (ROSC). Care focuses on restraining ongoing injury and preventing cardiac arrest recurrence during all phases: (1) immediate, the first $0-20$ minutes after ROSC; (2) early, the period after ROSC from 20 minutes up to 6-12 hours; (3) intermediate, $12-72$ hours; (4) recovery, approximately 72 hours to day 7 , the start of which may be influenced by factors such as cardiovascular function or the use of therapeutic hypothermia (TH); and (5) rehabilitation. ${ }^{1)}$ The first 3 phases involve hypoxemic-hypotensive perfusion with energy deprivation. With ROSC, there is a burst of reactive oxygen, and oxidative stress may arise in tissue that is depleted of antioxidants.

PCAC must begin promptly after ROSC with a focus on supporting initial end-organ function, anticipating and treating the post-cardiac arrest syndrome, and addressing the underly. ing cause of the arrest. TH was intentionally used for potential neuroprotection after traumatic or anoxic brain injury or encephalitis. ${ }^{1)}$ Targeted temperature management (TTM) covers a range of clinical interventions to control systemic temperature and includes both the induction of varying degrees of hypothermia and the prevention of fever ("targeted normothermia"). ${ }^{2}$ International guidelines recommend TH for adults with out-ofhospital cardiac arrest. ${ }^{3)}$ Another recent trial involving adults after out-of-hospital cardiac arrest documented that $\mathrm{TH}$ with a target temperature of $33^{\circ} \mathrm{C}$ versus actively maintained therapeutic normothermia $\left(\mathrm{TN} ; 36^{\circ} \mathrm{C}\right)$ did not improve outcomes. ${ }^{4)}$ However, there are significant differences in the etiologies, incidence, and outcomes of out-of-hospital cardiac arrest between adult and pediatric populations, and results cannot be generalized between age groups.

The Therapeutic Hypothermia after Pediatric Cardiac Arrest Out-of-Hospital randomized controlled trial (RCT) compared the efficacy of $\mathrm{TH}\left(33^{\circ} \mathrm{C}\right)$ with that of $\mathrm{TN}\left(36.8^{\circ} \mathrm{C}\right)$ in children. 5) A total of 295 children were randomized at 36 centers. The results showed no significant intergroup difference in the primary outcome of survival with a good neurobehavioral out- come score at 12 months. The secondary outcome, change in neurobehavioral outcome scores from baseline to 1 year, did not differ between groups. Mortality at 1 year did not differ significantly between the 2 groups, although survival over time was significantly longer with TH than with TN $(149 \pm 14$ days vs. $119 \pm 14$ days, $P=0.04)$. . $^{5}$

There are numerous differences between cardiac arrest occurring in the out-of-hospital versus in-hospital setting including patient demographics, pre-existing pathology, etiology, response times, and survival rates. The Therapeutic Hypothermia after Pediatric Cardiac Arrest trial researchers analyzed the pooled data from 2 RCTs and evaluated the comparative efficacy and safety of TH and TN for the treatment of children who experience out-of-hospital versus in-hospital cardiac arrest. ${ }^{6}$ A total of 624 patients were randomized at 47 centers. There was no remarkable improvement in survival with a favorable score of neurobehavioral outcomes for TH (28\%) versus TN (26\%). Mortality at 1 year was not significantly different between the 2 groups, although earlier deaths in the first 3 days of the intervention were noticed with TN. Further, the TH and TN groups had similar safety profiles for blood product use, infection, serious arrhythmia, and 28-day mortality. ${ }^{6}$ Their larger pooled cohort reported that $\mathrm{TH}$ did not confer a significant survival benefit with a good neurobehavioral outcome versus TN in children after cardiac arrest in the out-of-hospital or in-hospital setting. However, this pooled study involved a more heterogeneous population than either individual trial. Selecting a more homogeneous population or excluding the most severe hypoxicischemic arrests (e.g., sudden infant death syndrome) might enable a more thorough assessment of TTM efficacy.

The impact of TTM in neonatal hypoxic-ischemic encephalopathy (HIE) has been poorly studied until now. A Cochrane review of 11 RCTs that included 1,505 term and late preterm neonates with HIE concluded that $\mathrm{TH}$ significantly reduced mortality and severe disability at 18 months. ${ }^{7}$ In 2010, TH was accepted as the standard of care for term and near-term neonates with moderate to severe HIE in the United States. $\left.{ }^{8}\right)$ Although TH has improved outcomes, in the major RCTs, $40 \%-50 \%$ of

Corresponding author: Yun-Jin Lee, MD, PhD. Department of Pediatrics, Pusan National University Children's Hospital, 20 Geumo-ro, Yangsan 50612, Korea 凶E-mail: jinnyeye@hanmail.net, https://orcid.org/0000-0003-4727-7018

Received: 11 November, 2019, Revised: 11 February, 2020, Accepted: 18 February, 2020

This is an open-access article distributed under the terms of the Creative Commons Attribution Non-Commercial License (http://creativecommons.org/licenses/bync/4.0/) which permits unrestricted non-commercial use, distribution, and reproduction in any medium, provided the original work is properly cited.

Copyright (c) 2020 by The Korean Pediatric Society 
treated infants died or had considerable neurological disability. The use of TH for preterm infants with HIE has not been strictly studied, but reports have not verified its benefit. ${ }^{9)}$

The assessment for the prognostication should be multimodal and delayed until at least 72 hours after cardiac arrest. ${ }^{10)}$ Many unanswered questions remain regarding the ideal evaluation of TTM in pediatric neurocritical care, such as different durations and cooling depths, earlier TTM onset, and adjunctive neuroprotective agents. Physicians must recognize that the prognostic factors should be monitored during the first 3 phases of pediatric post-cardiac arrest and consider the appropriate therapeutic intervention to provide potential neuroprotection.

\section{Conflicts of interest}

No potential conflict of interest relevant to this article was reported.

See the article "How can neurological outcomes be predicted in comatose pediatric patients after out-of-hospital cardiac arrest?" via https://doi.org/10.3345/kjp.2019.00941.

\section{References}

1. Neumar RW, Nolan JP, Adrie C, Aibiki M, Berg RA, Böttiger BW, et al. Postcardiac arrest syndrome: epidemiology, pathophysiology, treatment, and prognostication. A consensus statement from the International Liaison Committee on Resuscitation (American Heart Association, Australian and New Zealand Council on Resuscitation, European Resuscitation Council, Heart and Stroke Foundation of Canada, InterAmerican Heart Foundation, Resuscitation Council of Asia, and the Resuscitation Council of Southern Africa); the American Heart Association Emergency Cardiovascular Care Committee; the Council on Cardiovascular Surgery and Anesthesia; the Council on Cardiopulmonary, Perioperative, and Critical Care; the Council on Clinical Cardiology; and the Stroke Council. Circulation 2008;118:2452-83.

2. Karnatovskaia LV, Wartenberg KE, Freeman WD. Therapeutic hypothermia for neuroprotection: history, mechanisms, risks, and clinical applications. Neurohospitalist 2014;4:153-63.

3. Peberdy MA, Callaway CW, Neumar RW, Geocadin RG, Zimmerman JL, Donnino M, et al. Part 9: post-cardiac arrest care: 2010 American Heart Association Guidelines for Cardiopulmonary Resuscitation and Emergency Cardiovascular Care. Circulation 2010;122(18 Suppl 3): S768-86.

4. Nielsen N, Wetterslev J, Cronberg T, Erlinge D, Gasche Y, Hassager C, et al. Targeted temperature management at $33^{\circ} \mathrm{C}$ versus $36^{\circ} \mathrm{C}$ after cardiac arrest. NEngl J Med 2013;369:2197-206.

5. Moler FW, Silverstein FS, Holubkov R, Slomine BS, Christensen JR, Nadkarni VM, et al. Therapeutic hypothermia after out-of-hospital cardiac arrest in children. NEngl J Med 2015;372:1898-908.

6. Scholefield BR, Silverstein FS, Telford R, Holubkov R, Slomine BS, Meert $\mathrm{KL}$, et al. Therapeutic hypothermia after paediatric cardiac arrest: Pooled randomized controlled trials. Resuscitation 2018;133:101-7.

7. Jacobs SE, Berg M, Hunt R, Tarnow-Mordi WO, Inder TE, Davis PG. Cooling for newborns with hypoxic ischaemic encephalopathy. Cochrane Database Syst Rev 2013;(1):CD003311.

8. Kattwinkel J, Perlman JM, Aziz K, Colby C, Fairchild K, Gallagher J, et al. Neonatal resuscitation: 2010 American Heart Association Guidelines for cardiopulmonary resuscitation and emergency cardiovascular care. Pediatrics 2010;126:e1400-13.

9. Rao R, Trivedi S, Vesoulis Z, Liao SM, Smyser CD, Mathur AM. Safety and short-term outcomes of therapeutic hypothermia in preterm neonates 34-35 weeks gestational age with hypoxic-ischemic encephalopathy. J Pediatr 2017;183:37-42.

10. Kim HJ. How can neurological outcomes be predicted in comatose pediatric patients after out-of-hospital cardiac arrest? Clin Exp Pediatr 2020 Feb 6 [Epub]. https://doi.org/10.3345/kjp.2019.00941. 